Karen Boyle, What's in a name? Theorising the Inter-relationships of gender and violence, Feminist Theory (Volume 20, Issue 1), pp. 19-36. Copyright (C) The Author 2018 Reprinted by permission of SAGE Publications.

\title{
What's in a name? Theorising the inter-relationships of gender and violence
}

\author{
Karen Boyle, University of Stirling
}

\begin{abstract}
This paper explores the representational practices of feminist theorising around gender and violence. Adapting Liz Kelly's notion of the continuum of women's experiences of sexual violence, I argue that 'continuum thinking' can offer important interventions which unsettle binaries, recognise grey areas in women's experiences and avoid 'othering' specific communities. Continuum thinking allows us to understand connections whilst nevertheless maintaining distinctions that are important conceptually, politically, legally. However, this is dependent upon recognising the multiplicity of continuums in feminist theorising - as well as in policy contexts - and the different ways in which they operate. A discussion of contemporary theory and policy suggests that this multiplicity is not always recognised, resulting in a flattening of distinctions which can make it difficult to recognise the specifically gendered patterns of violence and experience. I conclude by considering how focusing on men's behaviour might offer one way of unsettling the contemporary orthodoxy which equates gender-based violence and violence against women.
\end{abstract}

\section{Keywords}

Gender-based violence, gender violence, violence against women, domestic abuse, men's violence, continuum thinking.

\section{Introduction}

This article arose from a mistake. My mistake.

In April 2015, I was asked to speak about representations of sexual violence at London School of Economics' Gender Commission. When I had to provide a title for the paper, I did something not uncommon in academia: I hurriedly gave a title generic enough to enable me to work out specifics nearer the time. When that time arrived, I realised I had promised a paper on 'representing gender-based violence'. Although I had intended to talk about men's sexual violence against women, I had used a gender-neutral umbrella term. My paper became about this category error.

This article continues that work. By beginning with my mistake I want to highlight that this is not an investigation of 'other' representational practices, but rather of feminist theory itself, and its uneven absorption in policy and practice. After all, our linguistic choices are fundamentally conceptual (Cameron, 2014, 2016). Our words shape the ways in which it is (not) possible to understand the issues at stake, the ways they are legislated against, measured and resourced, and the responses which are deemed most urgent and appropriate. Yet, writing this article, I have realised how often category errors appear in my own work. Another example will illustrate this and introduce key themes to be explored in this article. 
Also in 2015, I co-wrote an application for a PhD studentship entitled 'Archiving and Historicising the Feminist Anti-Violence Movement in Scotland'. The italicised words were, I thought, an elegant solution to the problem of naming the movement and a reaction against the more common 'violence against women' (or VAW'), a term which I think problematically implies women's vulnerability rather than men's responsibility and omits a crucial detail: that this is a movement against violence against women. It implies that we accept that violence against women is an unchanging reality and our job is to support women in that context. That's not what I think feminist organisations $d o$, but our language makes it easy for others to infer this.

'Men's violence against women' didn't work either: some of the organisations do not work exclusively on men's violence but, for instance, also work against female genital mutilation which typically involves female perpetrators, even if acting in male interests. Indeed, it wasn't even exclusively violence against women: some key organisations also focused on men's sexual abuse of children - boys and girls. Mindful of my LSE 'mistake', I also rejected the anachronistic, gender-neutral, bureaucratic (Cameron, 2016) 'gender-based violence'.

And so we arrived at 'the feminist anti-violence movement'. Our project focuses specifically on feminist activism against inter-personal violence but - as Finn Mackay later pointed out the term we chose should also include women's peace activism. Our labelling had created unintended intersections, and new omissions.

This example introduces some of the key tensions in the definition and use of umbrella terms in this field. Is our focus on commonalities among victims (violence against women), perpetrators (men's violence), meaning (gendered or gender-based violence; sexual violence), or a theoretical and political approach (feminist)? This article focuses on varied conceptual intersections which feminists have sought to forge between different experiences and understandings of violence, and on the umbrella terms which have come to define the field. To discuss feminist approaches to connectivity, I introduce the term 'continuum thinking'. This draws on Liz Kelly's (1988) influential work on women's experiences of sexual violence in which she argues that the pervasive nature of men's sexual violence means that women make sense of individual actions in relation to a continuum of related experiences across a lifetime. For Kelly, the continuum can allow us to identify a 'basic common character that underlies many different events' and/or 'a continuous series of elements or events that pass into one another and cannot be readily distinguished' (1988: 76). Kelly's work has been adopted and adapted in a wide range of contexts to expose and explore connections between gender and violence. However, as contexts and connections vary, I argue here that it is necessary to think about continuums in the plural.

In the next section, I use 'domestic abuse' to begin to explore the implications of different ways of situating specific forms of men's violence against women. Naming practices make more or less visible who is doing what to whom, and foreground differing sets of connections. This leads into a discussion of continuum thinking in relation to 'gender-based violence', focusing on femicide to explore forms of connection this enables. This additionally opens up a consideration of some of the complexities of linking women's and children's experiences. The discussion of feminist debates about pornography and/as gender-based violence against women which follows, unravels some of the benefits and limitations of 
expansive definitions of violence encompassing representation as well as action. Finally, I turn my attention to continuum thinking as a means of analysing men's behaviours, suggesting that this challenges the equation of 'gender-based violence' with 'violence against women'. Nevertheless, my aim is not to advocate for uniformity in language or claim that one term is necessarily 'better' (more feminist) than another. In fact, my argument is the opposite of this: namely, that the value of continuum thinking is to see connections not equivalences, and so to insist on the importance of distinctions.

\section{From naming the abuse to gender neutrality}

Debates about naming are essentially about context and connection: what else is this like? In Women's Liberation Movement activism, finding a language for women's experiences of abuse - previously normalised or rendered invisible - was crucial. Feminist consciousnessraising allowed women to identify and understand the gendered, structural nature of their individual experiences of male violence. This allowed women to name certain forms of men's violence and abuse for the first time - wife-battering (Dobash and Dobash, 1979), incest (Armstrong, 1978), sexual harassment (MacKinnon, 1979). This process of uncovering women's experiences and naming abuse has continued up to recent work on, for example, technology-facilitated sexual violence (Henry and Powell, 2015a, 2015b) or image-based abuse (McGlynn et al., 2017). But what is important about feminist naming practices is that they take place within an analysis of patriarchy in which an understanding of gender inequality is essential. Across different contexts (public/ private; offline/online), relationships (intimate/ familial/ collegial/ acquaintance/ stranger), temporalities (one-off/ repeated/ sustained) and cultures, feminists ask what these experiences have in common and how they differ?

As knowledge and understanding of the issues has shifted, so too has our language. For example, early work on men's abuse of their intimate partners often used terms like 'wife battering'. As our understandings of intimate relationships and the spectrum of men's abuse of women within those contexts developed, this language changed. The relationship of perpetrator to victim is still understood to define this kind of abuse (highlighted by terms such as domestic or intimate partner), but language which implies only physical assault (violence, battering) has been questioned. Can 'abuse' better encapsulate the range of physically, emotionally, financially and sexually controlling behaviours women experience? Or does this minimise the severity of specific violent incidents? Feminists have also been critical of the use of 'domestic' and 'intimate' as qualifiers, arguing that they imply a less severe form of violence, and the complicity of victims (Pain, 2014: 534). As these examples suggest, finding the right language remains a challenge, not least because of the need to allow women to name the everydayness of their experiences on the one hand, without minimising the severity (and, implicitly, criminality) of specific experiences on the other.

More recently, 'coercive control' (Stark, 2009) has entered the lexicon as a way of trying to address this problem, focusing on conceptualising domestic abuse as ongoing and cumulative. Stark's work highlights the ways in which men's physical abuse of female partners is interwoven with intimidation, isolation and control such that the meaning of individual actions cannot be understood independent of the broader context in which they 
occur. An act which may seem innocuous in another context can be experienced very differently as part of a pattern of behaviour extending over decades: echoing Kelly's conceptualisation of the continuum of women's experiences over a lifetime.

Although coercive control is becoming more widely understood in policy contexts, the gendered analysis of domestic abuse is inconsistently maintained. Stark's work is, in part, a response to inter/national surveys which find more equivalence in men's and women's rates of victimisation within intimate partnerships than might be expected (Walby et al., 2017). As Kelly and Westmarland (2014) argue, such suggestions of equivalence arise from attempts to define domestic abuse both through individual incidents (a punch, slap, etc.) and through controlling behaviours of long duration. A single push can be given the same statistical weight as repeated threats to kill.

Indeed, it is now becoming increasingly common to see a 'dual focus' (Walby et al., 2017: 24) on 'violence against women and domestic violence' (Council of Europe, 2011: 1) or 'gender-based and intimate partner violence' (EIGE, 2015: 20) in policy contexts. This seems intended to acknowledge the experiences of male victims as well as the abuse of both women and men in same-sex partnerships (on the basis of victimisation surveys referred to above). But conjoining these terms implies that domestic abuse is not violence against women, or gender-based violence. It means losing sight of the specific feminist analysis of men's abuse of women in intimate relationships. This is not to deny the existence of women's violence against intimate partners of any gender. More simply, it is to ask what we gain by making connections based on the status of the relationship rather than the broader socio-cultural context in which that relationship - and the people in it - exist.

Notably - unlike wife battering - terms like domestic abuse, intimate partner violence and even coercive control are gender neutral. Indeed, Stark acknowledges the particular intersections coercive control brings to the fore:

At the core of coercive control theory is the analogy to other capture crimes like hostage taking or kidnapping, a comparison that illustrates what Elizabeth Schneider calls its 'generality.' [...] The singular advantage of the analogy is that it links women's predicament in personal life to the larger discourse of rights and liberties we apply to citizen-victims, including the human rights discourse, implicitly undermining a major rationale that limits justice intervention in what are deemed just family matters. By using the gender-neutral language of power and control to frame abuse, the hostage analogy also supports an approach women have repeatedly used to gain legal rights men already possess, such as the right to vote or sit on juries.

(Stark, 2009: 365)

Stark is not alone in seeing benefits in linking men's routinised abuse of women in intimate partnerships with a 'larger', gender-neutral discourse. Catharine MacKinnon, for instance, has argued for conceptualising rape as torture (1993a) and Rachel Pain $(2012,2014)$ has made compelling connections between global terrorism and domestic abuse. However, situating rape and domestic abuse - most commonly experienced by women in private - in relation to hostage-taking, torture and terrorism runs the risk that women's experiences of male violence can only be recognised analogously - when they can be related to experiences 
of violence in which victims are not, typically, targeted because of their gender. As Clare McGlynn (2008) notes in relation to MacKinnon's rape-as-torture argument, there is also a danger that using such extreme analogies disguises or minimises - not least to women themselves (Gavey, 2005) - experiences of male violence which do not cause explicit or long-term injury or fear. There is a curious paradox here: men's violence against women is most visible when its gendered dimension is denied and when it looks most like men's own experiences of extreme violence (also Nayak and Suchland, 2006: 472).

\section{Continuities in meaning: gender-based violence}

Although I have focused so far on men's violence against women, the 'basic common character' underlying women's experiences of abuse is not always a male perpetrator, but rather the broader social meaning of the abuse: that women are targeted because they are women. This is now commonly taken as the basis of definitions of violence as gender based. Indeed, in international policy contexts violence against women is increasingly defined as violence which is gender based: 'Violence against women (VAW) is a form of gender-based violence that affects women excessively as it is directly connected with the unequal distribution of power between women and men, which perpetuates the devaluation and subordination of women and violates women's fundamental rights and freedoms.' (EIGE, 2015: 3)

In this widely-used definition, violence against women is a subset of gender-based violence. The terms are not strictly synonymous, although they are often treated as such (Nayak and Suchland, 2006: 468). What do we gain from thinking about violence against women (an umbrella concept which centres the experiences of women as victims/survivors of violence) as gender-based violence (an umbrella concept which focuses on the meaning of violence, rather than the identities of victims or perpetrators)?

A useful example for considering this question is the term 'femicide' (Radford and Russell, 1992). The coining of this term is not (only) a question of semantics - highlighting the linguistic male assumption in homicide - but rather names a specific form of homicide: the murder of women because they are women. This is differentiated not only from male homicide but also from the murder of women in other contexts (e.g. indiscriminate spree shootings). Femicide tells us both who the victim is and why they have been targeted.

Although femicide remains under-researched (Weil, 2016), one of the advantages of conceptualising the murder of women because they are women - as distinct from female homicide - is that it allows us to understand femicide on the continuum of (men's) violence against women (Radford and Russell, 1992). As, globally, women are far more likely than men to be murdered by an intimate partner or family member (Walby et al., 2017: 2; Dobash and Dobash, 2015), this brings into view the inter-connections of femicide and men's abuse of women in intimate relationships and allows us, for instance, to make sense of women's (rational) fear of leaving abusive men (Stark, 2009; Dobash and Dobash, 2015: 28). 
Yet, theorising femicide as the murder of women because they are women does not, necessarily, presuppose a male perpetrator. One area of femicide which sometimes involves female perpetrators is lethal 'honour-based' violence." Aisha Gill (2011) argues that placing 'honour-based' violence on the continuum of gender-based violence against women allows us to see continuities across cultures, challenging the notion that cultural values provide a unique justification for these crimes. This is particularly significant when the communities that perpetrate 'honour-based' violence are (ethnic) minorities within a dominant cultural context (such as South Asian communities in the UK). Here the continuum becomes a powerful tool in resisting the 'othering' of these communities, instead understanding the connections between violence against women in the name of 'honour' and forms of genderbased violence against women in the dominant culture, such as domestic abuse (Gill, 2011: 222). Expanding the continuum in this way means including acts which involve female perpetrators (albeit a minority). But asking who benefits helps to keep the role of patriarchal structures in view. This leads Nicole Westmarland (2015: xvi) to include honour-based violence, forced marriage and female genital mutilation as practices of men's violences, noting that they are 'acts by women [...] used to uphold men's privilege and support women's inequality'.

In her work on forced marriage, Gill - along with Sundari Anitha - also deploys a continuum based on women's experiences. Anitha and Gill (2009: 165) here refer to consent and coercion in relation to marriage as 'two ends of a continuum, between which lie degrees of socio-cultural expectation, control, persuasion, pressure, threat and force'. As with the research which led Kelly to propose the continuum of sexual violence (1988), Anitha and Gill are able to highlight important connections between women's everyday experiences - of constraints on marital consent - and criminal, violent acts against them. Anitha and Gill are interested in two ways of conceptualising forced marriage, then: as part of a 'continuum of choice and coercion' (2009: 165) linked to limitations imposed by 'compulsory heterosexuality' (Rich, 1980) and culturally-specific gender roles; and as 'a specific manifestation of a wider problem of violence against women' (Anitha and Gill, 2009: 166). They are concerned with dismantling binary ways of thinking which have disadvantaged women (not least in the legal system) when their experiences have occupied a 'grey area' inbetween coercion and consent, or violence and non-violence. Of course, these two conceptualisations are linked: compulsory heterosexuality is enforced by violence; violence is underpinned by constructions of heterosexually-appropriate gender roles (Gavey, 2005). But they are not the same: women can and do make positive choices about heterosexuality and marriage - which is not to say all women can or do.

In a 2012 article, Kelly notes (2012: xix) that the everyday, routine, intimate intrusions which were so key to her respondents' experiences of sexual violence over the course of a lifetime - and thus foundational to the concept of the continuum - dropped off many agendas in the intervening years because of the emphasis in much scholarship (and activism) on crime. Recent work like Anitha and Gill's - as well as the Everyday Sexism Project (Bates, 2014), Hollaback movement (https://www.ihollaback.org), or Fiona Vera-Gray's (2016) work on street harassment, to give just a few examples- has done much to redress this. One of the implications of this approach is that, by focusing on women's experiences across our life cycles, the continuum makes connections between our experiences as adults and girls. 
Whether these connections can then be extended to include the experiences of boy children is one of the questions I will now explore.

\section{Women, children and gender-based violence}

Linking the experiences of women and children has been conceptually important for feminist analysis. Firstly, it acknowledges the simultaneity of some forms of men's abuse of women and children (of all genders). In particular, the co-existence of the (domestic) abuse of women and children within the same household points to the impossibility of creating mutually exclusive categories' (Kelly et al., 1996: 86). However, where the abuse of women and children overlap in this way, the abuse of children also needs to be understood as gender based: the children are targeted because of their significance within the household gender dynamics, including in cases of murder (Dobash and Dobash, 2015). However, not all abuse of children (in the home or outside) is gender based. Terminology such as 'violence against women and children' can suggest false equivalences between different groups of victims and water down a gendered analysis of (men's) violence.

This is apparent in a Scottish Government (2017) consultation on the draft Delivery Plan for Equally Safe, Scotland's strategy to prevent and eradicate violence against women and girls. Despite the emphasis on women and girls in the original Strategy (Scottish Government, 2014), the draft Delivery Plan 'explicitly includes children of all genders' and aims to 'improve the lives and experiences of all children affected by violence' (Scottish Government, 2017: 3, emphasis mine). Here, the parallels between women and children appear to be drawn on the basis of an assumed shared vulnerability, rather than a genderbased analysis of why and how women and children are targeted by men in domestic and other contexts. Of course, improving the lives and experiences of all children affected by violence is essential. But adding 'children' into a plan focusing on violence against women and girls suggests a conceptual confusion which may have practical implications as very different stakeholders (women's organisations, children's organisations) make claims on a specific, limited, pot of resources. It is important work. But why should it sit within this strategy?

In contrast, thinking of continuities in women's experiences across time allows us to make conceptual linkages between child and woman abuse specific to girl children. This highlights the everydayness of men's attempts to control women and girls and the ways in which our understandings of our gendered selves are shaped through these (inter)actions from childhood onwards. This is not to argue that women and girls are always and only victims but rather to consider the diverse ways in which we accommodate, collude, cope, resist and survive. It sees victimisation and survival as (moving) points on a continuum, rather than as binary and all-consuming identities (Kelly et al,, 1996). ${ }^{i i i}$ An individual's movement across this continuum is not uni-directional or strictly chronological (such that, for instance, child victim becomes adult survivor). This is a dynamic way of understanding girls' and women's multi-faceted experiences of victimisation and survival in relation to male violence.

Nevertheless, establishing connections between children and women has opened feminists up to criticism that we infantilise women and downplay agency, whether in relation to 
sexual violence (see Kelly, Burton and Regan, 1996 for a discussion) or prostitution and pornography (Doezema, 2010). I will consider the challenges in conceptualising pornography on a continuum of men's sexual violence against women in the next section. Here I want to highlight that the distinction between children's and women's experiences of prostitution and pornography is typically configured in relation to sexual consent. Legally, children cannot consent to sex and so cannot consent to involvement in prostitution or pornography. As the terms 'prostitution' and 'pornography' foreground sex - and construct perpetrators as consumers - to pair either with 'child' is to fundamentally distort relations of power, control and the impossibility of consent. As such, feminists (and children's organisations) insist on making abuse visible with terms such as 'child abuse images' and 'the abuse of children in prostitution' (Women's Views on News, 2016). This is important, and brings power and the question of who benefits back into the equation. ${ }^{\text {iv }}$

But the possibility of an adult woman's sexual consent does not magically remove coercion. What happens when children abused in pornography become adults and 'choose' to perform in pornography or 'work' in prostitution? Does the harm automatically cease? The scare quotes here highlight the extent to which choice is always contingent and the conceptualisation of prostitution as sex work is contentious within feminism. This is not to say that no woman freely chooses to work in pornography or prostitution - nor is it to negate the importance of the possibility of choice, however constrained (Whisnant, 2004). However, as with Anitha and Gill's work on 'honour-based' violence, using continuum thinking here opens up separate - but interlocking - continuums: 'a continuum of choice and coercion' which centres women's and children's experiences (rather than legal definitions of consent); and a continuum of sexual violence (in which not all adult women would situate all of their experiences of prostitution and pornography). This unseats any binary distinction between child and adult woman without collapsing these experiences into one: the advantage of continuum thinking is to identify the ways in which they are related, without treating them as synonymous. Further, if we ask the who benefits question this allows for a rather different set of connections to be established, conceptualising men's behaviour as buyers of women (and men, and children) in relation to broader ideas about men's sexuality, power and sexual entitlement. The importance of continuum thinking for understanding men's behaviour is something I will return to, but first I want to consider another set of challenges pornography poses for continuum thinking.

\section{Representational continuums}

There is not space here to rehearse the arguments about pornography as/ and violence against women, which I have, in any case, summarised elsewhere (Boyle, 2014). Instead, I want to consider how continuum thinking helps conceptualise the dual realities of pornography as both material practice (real bodies, doing real things) and form of representation (staged, photographed, filmed, written, drawn).

Recent strategies to make the abuses of pornography visible have included a challenge to the conceptual utility of the term itself. This has been most explicit in debates about socalled 'revenge porn', a term which has become a media stand-in for the non-consensual creation or sharing of sexual images. As with critiques of 'child pornography', defining these 
practices as pornography can be argued to downplay their seriousness as acts of abuse committed by flesh-and-blood perpetrators with real-life consequences for victims (McGlynn et al., 2017). Instead, McGlynn, Rackley and Hougton (2017) propose the term 'image-based abuse' in an article which explicitly uses Kelly's notion of the continuum in two ways. Firstly, describing the continuum of image-based abuse allows them to expand the discourse beyond 'revenge porn' to establish similarities with other forms of image-based abuse, including so-called 'upskirting', v' voyeurism offences, coercive spectatorship and sexualised photoshopping. By focusing on women's experiences, they are able to understand connections between practices which are otherwise very different: some involving 'fakery', others non-consensual production or distribution, but all causing material harms.

It is striking that much of the behaviour McGlynn and colleagues describe has been facilitated by technological developments. Linking this to the burgeoning scholarship on women's diverse experiences of sexualised abuse online (not all of which are image-based), image-based abuse may therefore be conceptualised on a continuum of technologyfacilitated sexual violence (Henry and Powell, 2015a, 2015b) which impacts and constrains women's engagement with the digital public sphere (Tandon et al., 2015; Jane, 2017). More broadly than this, McGlynn et al.'s second use of the continuum is to theorise image-based abuse as part of Kelly's (1988) longer continuum of women's experiences of men's sexual violence. This is important in establishing the ways in which apparently new forms of sexual violence are conceptually and experientially similar to more well-documented patterns of abuse. As with Anitha and Gill's work, these conceptualisations thus allow us to see multiple connections in different contexts and support the broader argument I am developing here about the value of (re)conceptualising Kelly's continuum in the plural.

Conceptualising pornography per se as (men's) violence against women remains fraught in feminist theory and activism. One of the criticisms often levied at feminists who take this approach is that they conflate symbolic violence (patterns of representation) with material violence (actions). Although not focusing on pornography specifically, Walby et al. (2017: 35 ) note that conflating gender inequality more broadly with violence against women specifically, runs the risk of stretching the definition of violence so far that nothing is not violence. As such, violence against women can become too amorphous to quantify - or resist.

Similar arguments circulate in relation to whether harmful speech should be understood as literal violence. Whilst feminists have long highlighted the ways in which speech acts can engender harm and produce discrimination (MacKinnon, 1993b), placing threatening speech on a continuum of sexual violence should not mean, for instance, equating speech with rape. The expansion of the understanding of harmful speech in many contexts to include speech causing offence, and the equation of this with literal, physical violence, has, indeed, been used to silence feminist critique (Jones, 2015). In classroom settings, an unthinking use of the 'trigger warning' has worrying implications in terms of closing down discussion on, for example, sexual violence (Halberstam, 2016). Whilst there are important discussions to be had about trauma, triggers and pedagogy, Jack Halberstam (2016) highlights a 'paternalistic normativity' in many of these encounters, assuming that survivors' experiences are uniform, that they are uniquely, extremely and permanently vulnerable, and that triggers are always 
literal. Here, it seems that continuum thinking has been abandoned in favour of analogous thinking (Cameron, 2014): claiming one thing - speech -is the same as the other (violence), rather than being willing to explore the 'grey area' which the continuum allows.

I want to insist, then, on the importance of continuum thinking as a means of making connections, whilst noting the importance of clarity in relation to the nature of these connections and the necessity of distinction within this. This also means thinking about continuums in the plural. For instance, the abusive production practices of much audiovisual pornography are appropriately positioned on a continuum of sexual violence that - to take a mainstream example - would not make sense for E.L. James' novel Fifty Shades of Grey (2012). On the other hand, the novel and hard core audio-visual pornography may exist on another continuum: a continuum of representations of sexual violence. To deploy another concept from Kelly, the representational continuum might provide a conducive context (Kelly, 2005, 2016) for additional, material acts of sexual violence: legitimating and supporting a culture of male sexual entitlement, dominance and coercive control (Boyle, 2017). Fifty Shades represents male sexual violence against women, and could be conducive to real-world violence, but it is not - in and of itself - violence against women. This is as true of the Fifty Shades films as it is of the novels, as (unlike in hardcore) there is an assumption that the sex (and sexual violence) is 'faked' - representation rather than real - in mainstream contexts.

So far, I have highlighted conceptual challenges - as well as advantages - arising from continuum thinking centring, to various extents, on women's experiences. In the final section, I want to consider some of the implications of a reorientation to more explicitly centre men's behaviours.

\section{The continuum of men's violences}

One of the key contributions of continuum thinking has been to establish the ways in which 'typical' and 'aberrant' male behaviour shades into one another (Kelly, 1988: 75). This demands that we pay attention not only to women's experiences of male behaviour, but also to that behaviour itself and how it is rendered meaningful for men. Here, the concept of 'hegemonic masculinity' is useful, pointing to a pattern of practices - not all of which are explicitly abusive, and which are enacted in culture and institutions as well as in gender performance and inter-personal relationships - which allow men's dominance over women to continue (Connell and Messerschmidt, 2005: 832). In this final section, I want to argue that it can be equally useful to feminist analysis to think of men's behaviours (rather than women's experiences) on a continuum.

The continuum of men's violences allows us to think of violence as being gender based not because of who it targets but, rather, because of how that violence is understood in relation to perpetrators' gender performances. This can allow us to make gendered sense of behaviours which don't seem to fit comfortably on the continuums we have explored so far.

For instance, in 2012, British entertainer Jimmy Savile was revealed to have been a serial sexual predator, his crimes spanning five decades. I have argued elsewhere (Boyle, 2017) for the importance of understanding Savile's crimes as gendered, but this might seem 
counterintuitive: although the majority of Savile's victims were girls and young women, he also abused boys and adult men. Yet, a large part of the reason he got away with it for so long was that his 'aberrant' behaviour was so clearly foreshadowed in 'typical' male behaviour which was highly visible and, indeed, celebrated. The way he sexualised his encounters with any and every woman and girl was a clear but, crucially, 'normal', display of male sexual entitlement which both victims and bystanders often struggled to identify as abusive or problematic. A woman could not have behaved in the same way. There is no doubt that both his behaviour - and institutional blindness to it - was gendered. His sexual assaults on men and boys need to be understood in this context, as a further expression of his masculine dominance and power (Boyle, 2017).

In the context of male violence against women specifically, Patrizia Romito powerfully argues:

it is acceptable to talk about violence, but never about male violence. Here, too, we have adapted to this convention so far. Also, the documents of international organisations and governments [...] talk about violence towards women and children, but almost never of male violence, even if they describe husbands raping, maltreating and killing their wives. Rereading this text and international documents, in which the adjective 'male' is added to the word violence, has the effect of a punch in the stomach, because it confronts us with a brutal reality. It is this reality we are trying to escape from when we use euphemisms or generic and imprecise terms.

(Romito, 2008: 5)

Whilst I agree with Romito's argument, I want to take it in a slightly different direction to argue that part of the feminist project in naming and documenting men's violence is making the constructed nature of masculinity visible, and hence creating spaces where men's rejection of violent norms is not only possible but desirable. For instance, when women kill this is seen as such an aberration that their gender is almost always remarked upon in media representations (Boyle, 2005). Yet when men kill, no qualifier is needed: it is assumed that a killer (batterer, torturer, terrorist) is male. By marking the term - male killer, male terrorist - we demand that rather than taking this conjunction for granted we think about it critically. This confronts us with a brutal reality, as Romito suggests, but it can also denaturalise male violence.

Is there any advantage of using continuum thinking in relation to this far broader category of male violence? Can we, for instance, make connections between global terrorism and domestic abuse which are not analogous but reflect 'a continuous series of elements or events that pass into one another and cannot be readily distinguished' (Kelly, 1988: 76)?

Some of the most high-profile acts of global terrorism and mass killings in recent years were committed by men with histories of attacks against known women. Writing in the Guardian, Hadley Freeman (2017) suggests a correlation between these men's gender-based violence against known women and their embrace of fundamentalist patriarchal belief systems ('of pretty much any major religion') which advocate wildly restrictive attitudes towards gender. Freeman points to the ways in which - in men's experiences - different forms of violence can serve similar purposes as expressions of patriarchal belief systems. Thus, although - for 
instance - most of the attacks with multiple victims did not specifically target women, understanding these attacks as continuous with the perpetrators' previous violence towards known women renders these men decidedly 'typical'. This also provides a way of punctuating the self-aggrandising narratives of male exceptionalism which too often circulate around spectacularly abusive men such as terrorists or serial killers (Cameron and Frazer, 1987). It allows us to recognise these individuals - and the stories that are told about their crimes - as generic, not exceptional (Boyle and Reburn, 2015).

There is also an important point here to be made about the way in which the routine minimisation of men's violence against women (in everyday life as well as in the courts) facilitates these more publicly spectacular acts by providing a free pass to perpetrators. In Jeff Hearn's (1998) work with men who abused known women he found that minimisation was endemic in men's accounts of their behaviour. In their work with men who murder their intimate partners, Dobash and Dobash $(2011,2015)$ have similarly documented patterns of denial, minimisation, victim-blaming, and deflecting responsibility. These play out not only in the way the men talk about their murder convictions, but also more broadly in their accounts and expectations of gendered relationships. Whilst making crucial connections between lethal and non-lethal violence against women, Dobash and Dobash (2011: 114) tellingly note that '[e]vidence about the actions and orientations of violent abusers and intimate partner murderers parallel reports of men who use violence in other contexts, especially violence against other men.'

In this respect, there are advantages to thinking about men's violence against other men at least in some circumstances - as gender based. However, three important caveats here. Firstly, this is not a biological argument: in arguing that this is gender-based violence to the extent that it is perpetrated by men because they are men I am referring to the ways in which they relate to and embody particular - often normative - constructions of gender roles. It is a constructionist, not an essentialist, argument. Secondly, I am arguing for the conceptual utility of this approach for understanding (and therefore working to eradicate) men's violence. I am not suggesting that this kind of reconceptualisation would work legally, for instance. Finally, whilst this might provide a useful lens through which to consider abusive men's behaviour, it does not necessarily help us to understand men's experiences of victimisation. Men are not necessarily targeted because they are men, nor is their experience of victimisation consistent with gender inequality (though it may be consistent with other vectors of oppression, such as race or class). There are exceptions of course: the explicit targeting of men who are (or seem to be) gay or trans, where they are attacked because of their perceived transgressions of dominant gender norms, for instance. But insisting that gender is not a synonym for women (and gender-based violence is not synonymous with violence against women) is not to argue that we simply add men to existing models - built on women's experiences of victimisation and survival - and stir. Women and men are differently positioned in relation to gender-based violence. Placing men in gender-based violence, more often means making men visible as perpetrators.

None of this is to deny that women can be perpetrators, or men victims. Rather, it is to highlight the conceptual limitations of the ways in which we currently frame gender-based violence, and argue that the inter-relationships between gender and violence are more multi-faceted than some models suggest. 


\section{Conclusion: continuing continuum thinking}

Continuum thinking has been an essential element of feminist theories of gender violence for decades and has become mainstream to the extent that policy and practice is (in some contexts) less focused on isolated acts of violence and more sensitive to the 'grey areas' of women's experiences and the connections between them. Continuum thinking has allowed us to make sense of experiences which had no name - or no name which women recognised - and to understand the ways in which gender violence is itself an expression of gender inequality. As I have outlined, continuum thinking has posed a series of challenges to established binaries such as violence/not violence, victim/survivor, real/virtual, child/adult, choice/constraint.

However, the attempt to encapsulate and name the diverse experiences on the continuums which link gender and violence has been fraught with difficulty and has not necessarily supported feminist ends. In particular, the too-frequent conflation of 'violence against women' and 'gender-based violence' performs a number of erasures which should be of concern to feminists. Simply naming gender does not mean that our analysis is genderedindeed, gender-based violence can be a worryingly gender-neutral term which flattens important differences in terms of who is doing what to whom, in which contexts, to which effects, and to whose overall benefit. As Sarah Moore's (2011) work on 'date rape' reminds us, just because a term starts off doing feminist work does not mean that it continues to do so. Further research is certainly warranted into the contexts and conditions in which gender-based violence is used - in policy, in practice, in theory, in the media - but this article has indicated the extent to which it should be approached (and used) critically and with caution in the meantime.

That said, the answer is not to abandon any of these terms or to claim one as inherently better (or worse) than the other, but to be alert and critical to the ways in which they are used and to think about the - conceptual, political, practical - work they enable us to do. We need to be conscious of the basis on which we seek to establish connections. Is our focus on commonalities among victims, perpetrators, meaning, kinds of behaviour, or a theoretical and political approach? Does our language accurately reflect this focus: do we talk about violence against women, men's violence, gender-based violence, choice and coercion, feminism? Obviously we need to be understood and, as Gill's work on 'honourbased' violence or McGlynn's on 'revenge porn' demonstrates, this sometimes means using language we are critical of as a starting point. However, these authors work hard to keep the contingency and limitations of the language in view even when they reproduce it in the interests of clarity. Sometimes we need to speak in two voices.

This plurality can also be usefully reflected by moving away from conceptualising 'the' continuum in the singular. What I have called continuum thinking is an important way of theorising the inter-relationships of gender and violence, but it also demonstrates that not everything is related in the same way and distinctions are important. We can and should be more explicit about the intersecting (but non-continuous) use of continuums to theorise different aspects of women's (and children's) experiences and men's behaviours. Kelly's 
related concept of the 'conducive context' $(2005,2016)$ offers another way of understanding the broader gendered social, political and cultural conditions which facilitate men's violence against women without watering down the term 'violence' so that - as Walby et al. (2017: 35) have cautioned - it means everything and nothing. In conclusion, whilst insisting on the importance of establishing connections, I am nevertheless cautious of a depoliticised or uncritical use of continuum thinking. As the 'mistake' at the beginning of this article attests, umbrella terms can obscure more than they reveal about the ways in which gender and violence are related.

\section{REFERENCES}

Anitha, Sundari and Gill, Aisha (2009) Coercion, Consent and the Forced Marriage Debate in the UK. Feminist Legal Studies 17(2): 165-184.

Armstrong, Louise (1978) Kiss Daddy Goodnight: A Speak-Out on Incest. New York: Pocket Books.

Bates, Laura (2014) Everyday Sexism. London: Simon \& Schuster.

Boyle, Karen (2005) Media and Violence: Gendering the Debates. Thousand Oaks: Sage.

Boyle, Karen (2014) 'Feminism and Pornography'. In: Mary Evans, Clare Hemmings, Marsha Henry, Hazel Johnstone, Sumi Madhok, Ania Plomien and Sadie Wearing (eds) Handbook of Feminist Theory. London \& Thousand Oaks: Sage, pp. 215-231.

Boyle, Karen (2017) 'Hiding in Plain Sight: Gender, Sexism and Press Coverage of the Jimmy Savile Case'. Journalism Studies (online first, 3 February 2017).

Boyle, Karen (2017) 'The Implications of Pornification: Pornography, the Mainstream, and False Equivalences'. In: Nancy Lombard (ed) Research Companion to Gender \& Violence. London: Routledge (forthcoming).

Boyle, Karen and Reburn, Jenny (2015) 'Portrait of a Serial Killer: Intertextuality and Gender in the Portrait Film'. Feminist Media Studies 15(2): 192-207.

Cameron, Debbie (2014) 'Minding our Language'. Trouble and Strife. Available at: http://www.troubleandstrife.org/new-articles/minding-our-language/ (accessed 1 May 2017).

Cameron, Debbie (2016) 'The Amazing Disappearing 'Women'. In: Language: A Feminist Guide. Available at: https://debuk.wordpress.com/2016/09/12/the-amazingdisappearing-women/ (accessed 1 May 2017).

Cameron, Deborah and Frazer, Elizabeth (1987) The Lust to Kill: A Feminist Investigation of Sexual Murder. Cambridge: Policy. 
Connell, RW and Messerschmidt, James W (2005) 'Hegemonic Masculinity: Rethinking the Concept'. Gender \& Society 19(6): 829-59.

Council of Europe (2011) Convention on Preventing and Combating Violence Against Women (Istanbul Convention). Available at: https://doi.org/10.5305/intelegamate.51.1.0106 (accessed 1 May 2017).

Dobash, Rebecca Emerson and Dobash, Russell P (1979) Violence Against Wives: A Case Against the Patriarchy. New York: Free Press.

Dobash, Rebecca Emerson and Dobash, Russell P (2011) 'What Were They Thinking? Men Who Murder an Intimate Partner'. Violence Against Women 17(1), pp.111-134.

Dobash, Rebecca Emerson and Dobash, Russell P (2015) When Men Murder Women. Oxford: Oxford University Press.

Doezema, Jo (2010) Sex Slaves and Discourse Masters: The Construction of Trafficking. London and New York: Zed.

European Institute for Gender Equality (2015) Strategic Framework on Violence Against Women: 2015 - 2018. Available at: https://doi.org/10.2839/4937782 (accessed 1 May 2017).

Freeman, Hadley (2017) 'What do Many Lone attackers Have in Common? Domestic Violence'. Guardian, 28 March. Available at: https://www.theguardian.com/commentisfree/2017/mar/28/lone-attackers-domesticviolence-khalid-masood-westminster-attacks-terrorism (accessed 1 May 2017).

Gavey, Nicola (2005) Just Sex? The Cultural Scaffolding of Rape. London and New York: Routledge.

Gill, Aisha (2011) 'Reconfiguring 'Honour'-Based Violence as a Form of Gendered Violence'. In: Mohammad Mazher Idriss and Tahir Abbas (eds), Honour, Violence, Women and Islam. Abingdon: Routledge, pp. 218-231.

Halberstam, Jack (2016) 'Trigger happy: From content warning to censorship'. Signs Currents: Feminist Key Concepts and Controversies. Available at: http://signsjournal.org/currents-trigger-warnings/halberstam/ (accessed 20 July 2017).

Hearn, Jeff (1998) The Violences of Men: How Men Talk About And How Agencies Respond to Men's Violence. Thousand Oaks: Sage.

Henry, Nicola and Powell, Anastasia (2015a) 'Beyond the "Sext": Technology-Facilitated Sexual Violence and Harassment Against Adult Women'. Australian \& New Zealand Journal of Criminology 48(1): 104-118.

Henry, Nicola and Powell, Anastasia (2015b) 'Embodied Harms: Gender, Shame, and Technology-Facilitated Sexual Violence. Violence Against Women 21(6): 758-779. 
James, EL (2012) Fifty Shades of Grey. London: Arrow.

Jane, Emma (2017) Misogyny Online: A Short (and Brutish) History. Thousand Oaks: Sage.

Jones, Jane Clare (2015) "You are Killing Me': On Hate Speech and Feminist Silencing'.

Trouble and Strife. Available at: http://www.troubleandstrife.org/new-articles/you-are-

killing-me/ (accessed 20 July 2017).

Kelly, Liz (1988) Surviving Sexual Violence. Cambridge: Polity.

Kelly, Liz (2005) Fertile Fields: Trafficking in Persons in Central Asia. Vienna: International Organization for Migration. Available at:

https://publications.iom.int/system/files/pdf/fertile fields.pdf (accessed 1 May 2017).

Kelly, Liz (2012) 'Standing the Test of Time? Reflections on the Concept of the Continuum of Sexual Violence'. In: Jennifer M. Brown and Sandra L. Walklate (eds), Handbook on Sexual Violence. London: Routledge, pp. xvii-xxvi.

Kelly, Liz (2016) 'The Conducive Context of Violence Against Women and Girls', Discoversociety, 1 March. Available at:

http://discoversociety.org/2016/03/01/theorising-violence-against-women-and-girls/ (accessed 1 May 2017).

Kelly, Liz, Burton, Sheila and Regan, Linda (1996) 'Beyond Victim or Survivor: Sexual Violence, Identity and Feminist Theory and Practice'. In: Lisa Adkins and Vicki Merchant (eds), Sexualizing the Social: Power and the Organization of Sexuality. Basingstoke: Macmillan, pp. 77-101.

Kelly, Liz and Westmarland, Nicole (2014) 'Time for a Rethink - Why the Current Government Definition of Domestic Violence is a Problem'. In: Trouble \& Strife. Available at: http://www.troubleandstrife.org/2014/04/time-for-a-rethink-why-thecurrent-government-definition-of-domestic-violence-is-a-problem/ (accessed 1 May 2017).

McGlynn, Clare (2008) 'Rape as "torture"? Catharine Mackinnon and questions of feminist strategy’. Feminist Legal Studies 16(1): 71-85.

McGlynn, Clare, Rackley, Erika and Houghton, Ruth (2017) 'Beyond "revenge porn": The continuum of image-based sexual abuse'. Feminist Legal Studies. Online first: 16 March.

MacKinnon, Catharine (1979) Sexual Harassment of Working Women: A Case of Sex Discrimination. New Haven: Yale University Press.

MacKinnon, Catharine (1993a) 'On Torture: A Feminist Perspective on Human Rights. In: Kathleen E. Mahoney and Paul Mahoney (eds) Human Rights in the Twenty-First Century: A Global Challenge. The Hague: Martinus Nijhoff, pp.21-31. 
MacKinnon, Catharine (1993b) Only Words. Cambridge: Harvard University Press.

Moore, Sarah EH (2011) 'Tracing the Life of a Crime Category'. Feminist Media Studies 11(4): 451-465.

Nayak, Meghana and Suchland, Jennifer (2006) 'Gender Violence and Hegemonic Projects'. International Feminist Journal of Politics 8(4): 467-485.

Pain, Rachel (2012) Everyday Terrorism: How Fear Works in Domestic Abuse'. Report, Scottish Women's Aid. Available at: http://www.scottishwomensaid.org.uk/node/145 (accessed 1 May 2017).

Pain, Rachel (2014) 'Everyday Terrorism: Connecting Domestic Violence and Global Terrorism'. Progress in Human Geography 38(4): 531-550.

Radford, Jill and Russell, Diana (1992) Femicide: The Politics of Woman Killing. Buckingham: Open University Press.

Rich, Adrienne (1980) 'Compulsory Heterosexuality and Lesbian Existence'. Signs 5(4): 63160.

Romito, Patrizia (2008) A Deafening Silence - Hidden Violence Against Women and Children. Bristol: Policy.

Scottish Government (2017) Equally Safe - Consultation on a Draft Delivery Plan. Available at: https://consult.scotland.gov.uk/violence-against-women-team/equally-safe/ (accessed 14 May 2017).

Scottish Government (2014) Equally Safe: Scotland's Strategy for Preventing and Eradicating Violence Against Women and Girls. Available at:

http://www.gov.scot/Resource/0046/00463546.pdf (accessed 14 May 2017).

Stark, Evan (2009) Coercive Control: How Men Entrap Women in Personal Life. Oxford:

Oxford University Press.

Tandon, Nidhi and Pritchard, Shannon (2015) Cyber Violence Against Women and Girls. A World-Wide Wake-up Call. UN. Available at: http://www.unwomen.org/en/digitallibrary/publications/2015/9/cyber-violence-against-women-and-girls (accessed 20 July 2017).

Vera-Gray, Fiona (2016) Men's Intrusion, Women's Embodiment: A Critical Analysis of Street Harassment. London \& New York: Routledge.

Walby, Sylvia; Towers, Jude; Balderston, Susie; Corradi, Consuelo; Francis, Brian; Heiskanen, Markku; Helweg-Larsen, Karin; Mergaert, Lut; Olive, Philippa; Palmer, Emma; Stöckl, Heidi and Strid, Sofia (2017) The Concept and Measurement of Violence Against Women and Men. Bristol: Policy Press. 
Weil, Shalva (2016) 'Making Femicide Visible'. Current Sociology 64(7): 1124-1137.

Westmarland, Nicole (2015) Violence Against Women: Criminological Perspectives on Men's Violences. London \& New York: Routledge.

Whisnant, Rebecca (2004) 'Confronting Pornography: Some Conceptual Basics'. In: Christine Stark and Rebecca Whisnant (eds) Not For Sale: Feminists Resisting Prostitution and Pornography, Melbourne: Spinifex, pp. 15-27.

Women's Views on News (2016). 'There is No Such Thing as a Child Prostitute'. Available at: http://www.womensviewsonnews.org/2016/04/there-is-no-such-thing-as-a-childprostitute/ (accessed 14 May 2017).

\footnotetext{
' It would have been less cumbersome to have adopted abbreviations such as VAW (violence against women) and GBV (gender-based violence) in this article. However, such acronyms are arguably another means of obscuring the gendered specificity of violence and also point to an increasingly bureaucratic register (Cameron, 2016). As such, I have resisted the use of acronyms unless in direct quotation.

ii Although commonly used, the term 'honour'-based violence problematically centres male understandings of honour. For a discussion of the term, see Gill (2011).

iii In her initial formulation of the continuum, Kelly (1988) was careful to note that the continuum was neither linear not hierarchical in terms of severity of violence, with the important exception of lethal violence. This exception is equally crucial to thinking of experiences of victimisation and survival as movable points on a continuum.

iv Although there is not the space to explore this here, it is important to note that whilst there is always a power differential between children abused in prostitution and the men who 'buy' them, there are grey areas in relation to sexual images of children when produced by children of themselves, for themselves. As Henry and Powell (2015a) argue, rather than an automatic assumption of a lack of consent in children's sexting (and an assumption of consent in adult practices), thinking of a continuum of consent and coercion in a broader gendered social sphere can be helpful in avoiding stigmatising (or even criminalising) children for their practices.

$\checkmark$ 'Upskirting' involves 'the consensual taking of images of an individual's public area underneath their outer clothing in public places' (McGlynn et al., 2017).
} 